\title{
Discussion on financial management strategy of group enterprise based on Internet
}

\author{
Ruoming $\mathrm{Tang}^{1}$, Cong $\mathrm{Li}^{1}{ }^{*}$ \\ ${ }^{1}$ Hainan University,Danzhou city Hainan Province 571737, China \\ *licong8866@qq.com
}

Keywords: Countermeasures Internet environment; financial management; strategy discussion

\begin{abstract}
At present, with the development of science and technology, Internet technology has become more and more widely used in people's life, and its contribution to the progress of human society is obvious to all. In the background of a market economy, great achievements have been made in the economic development of our country. The emergence of group enterprises has provided the impetus for the healthy development of China's market economy. In the process of the progress of the group enterprise, the financial problem of the enterprise is the key factor that affects the development of the group. Internet technology not only improves the accuracy of financial management and effective application in the enterprise group financial management, improve the efficiency of the job, at the same time, also caused some negative impact on the financial management, which requires enterprises to improve work constantly to substitute their own management level and the system.
\end{abstract}

\section{Introduction}

In the Internet technology continues to develop today. The group enterprise financial management has become more and faster, this is the Internet and the development of science and technology for enterprise development brings convenience. In financial management, the application of the Internet cannot only the enterprise financial management information collection and classification, and also can design and perfect the procedure makes the financial management more standardized and professional working group. Therefore, the application of Internet technology in the fiscal management of the group enterprises is an important technical means to improve the business results and improve the quality of enterprise management. However, science and technology are a double-edged sword. In the promotion of financial management level of enterprises at the same time there are many negative effects, which require the enterprise management and financial management personnel to study for the problems.[1]

\section{The modern characteristics of financial management of group enterprises under the Internet Environment}

At present, as China's market economy continues to advance and develop, China's economic development has gradually entered a critical period of deepening reform. While enterprises as participants in the market economy, we need to constantly adjust its development strategy in the process of economic transformation in the market, and constantly improve their own management ability and decision-making ability, through the establishment of modern enterprise system and modern financial management system to ensure the healthy and sustainable development of enterprises, it is not only the requirements of the enterprise, or the basic requirements to promote China's economic development, building a modern nation. In a period of rapid economic development, China's enterprises have a strong cooperation trend, and the group in the form of more and more enterprises, a group of enterprises can ensure that the subsidiary can develop continuously in the good development of the parent company's lead, promote the economic efficiency of enterprises; on the other hand, group business risk increases, once a key part of the problem, then the whole group will be affected, and even there will be a big problem for the survival of the group. 
Therefore, it is very necessary to discuss and study the financial management strategy for the different characteristics of the group enterprise under the Internet environment.[2]

\section{The Influence of the Internet environment on the financial management of group enterprises}

The impact of Internet environment on the financial management objectives of group enterprises. In twenty-first Century, with the development of science and technology and the application of Internet in group enterprises, enterprises have changed in everyday administration and financial management. Group enterprise because of its particularity of its profit model and business model is changing with the change of market economy, therefore the enterprise economy also changed, and with the business model changes constantly adjust, the specific performance in the business process will gradually improve the technology innovation and knowledge capital the strategic height of enterprise development is high, and in response to drive innovation and central government advocates and the supply side reform policies, pay more attention to the innovation ability of the enterprise and the enterprise culture construction. The new period, the change of enterprise management model makes enterprises to obtain economic benefits has changed, which requires the financial management of the enterprise group can follow the economic benefits of the enterprise changes, on the one hand and constantly improve their own professional strength and the level of financial management; the other one is to change the development mode and concept development the key to talent and knowledge transfer. Through the enterprise financial management, enterprise development goals and social development goals can be unified, so as to ensure that the development of enterprises in line with social progress law.

The influence of Internet environment on the financial management model of group enterprises. Before the Internet application in the enterprise financial management, the group enterprise has paid great attention to the fiscal forecast work, and placed it in the extremely important position. Financial prediction is not only related to the beneficial operation of enterprise funds, but also related to the effectiveness of enterprise financial management. Therefore, the group enterprise will carry out the financial forecast before the capital is put into operation, and this prediction is mainly artificial, whose judgment is based on the past experience and the authenticity of the data. However, in the application of Internet technology to the group financial management, the enterprise financial management model has undergone tremendous changes. It is mainly the following points: first, the enterprise information collection is mainly dependent on the cyber source, which can not only enhance the staff of financial management of the data collection speed and efficiency, but also can guarantee the accuracy of data and authenticity. However, corresponding to the traditional monetary management model and capital prediction mechanism of the group enterprises. Second, group enterprises in the implementation of financial planning and planning work, the traditional method can be based on past experience and market environment prediction and judgment on the future development of the enterprise, guarantee the correctness. But in the Internet environment, the update speed is beyond the imagination of the people and acceptance rate, in addition, the enterprise financial management personnel and management to ensure the authenticity and accuracy of all kinds of information in the Internet, so it is easy to cause the information decision-making mistakes, and ultimately affect the development of enterprises. Third, the Internet environment affects the implementation of enterprise decision-making. The traditional enterprise financial management model summary, financial management personnel can accord to exist experience and data to develop enterprise management strategy and program, and through effective communication for decision-making implementation and implementation. However, in the Internet environment, great changes have taken place in the traditional financial management mode of enterprise, decision-making mechanism can not guarantee that the subordinate authorities can experience its meaning accurately in order, and the group headquarters for the company of other industries and departments of information understanding is not enough, it is easy to cause the information security risks.[3] 
The influence of Internet environment on the financial management workflow of group enterprise. The characteristics of the fiscal management of the group enterprises mainly show that the departments are numerous and complex, and the establishment of institutions has an important impact on the efficiency of the work. In the outmoded financial management mode of group enterprises, their work depends on the communication and settlement of financial personnel, and this mode of work has a serious negative impact on efficiency. Not only affects the efficiency of financial management work, making time differences between departments, but also affect the enthusiasm of the financial management staff and ordinary employees. However, its rationality lies in the ability to manage the correctness of the process and the accuracy of the management mechanism. The application of Internet technology in the enterprise group, has changed the traditional financial management process, not only improve the efficiency of financial management, financial management and makes the process more direct and concise, a savings of enterprise financial management, making the same amount of work to be done enough in a shorter period of time. On the other hand, the financial management process is more specialized, and the Internet environment, it can reflect the professionalism of the group enterprises. However, in the Internet environment, enterprise financial management process changes in financial management staff can arrange the time at work, it has some unavoidable problems between the various departments is very easy to cause the enterprise group and financial management department.[4]

The influence of Internet environment on the financial management and information security of group enterprises. In the era of information, ensure that information security has been the key to the development of the times. As a participator of market economy, the financial information security of group enterprises is related to the good development of enterprises and the image of enterprises. The application of Internet technology in the fiscal management of group enterprises improves the management efficiency of enterprise information on the one hand, and also provides convenience for some illegal personnel to steal information on the other hand. At present, in the financial management of the enterprise group, enterprise database is an important storage space of financial information storage enterprise, and equipped with strong security protection mode, but with the development of science and technology, information security technology has become one of the main problems of enterprise financial management under the environment of internet. The group enterprise financial data security threats include network virus, hacker attacks and other factors, but the enterprise information maintenance technology Co., makes enterprises at a disadvantage in the process of maintaining information security, although in the $\mathrm{R} \& \mathrm{D}$ and innovation invested a lot of manpower and material resources, but always have little effect.

\section{Enhance the group enterprise financial management strategy}

Change the concept of enterprise financial management. The speed of social development under the environment of Internet speed, change information and concept changing, so we need to group enterprise managers and staff to change the work idea and positive attitude, especially the top managers and financial managers can change the idea as the guide and the traveler. In the Internet technology update and speed up the application of enterprises under the background of financial enterprises need managers and employees can will change the management concept and attitude to work in a prominent position, even in the enterprise strategic development position, will be incorporated into the construction of enterprise culture in . To change the concept and attitude of work, we have to make use of the advantages of the Internet to organize and divide the assets of enterprises. On the one hand, in the financial management of enterprises, enterprise capital classification, based on the knowledge of the original enterprise group cost accumulation, clearly divided according to the existing stage of the asset management plan and financial management program, in the process of consolidation plan in combination group to the future development of the enterprise status and management strategy to collate and refinement, this can help the enterprise financial management staff have intuitive understanding of the advantages of resources and capital situation of the enterprise, help the staff of financial management work can be more accurate for the 
analysis of enterprise capital structure and financial risk prediction. On the other hand, financial managers should also focus their attention on the Internet and analyze and judge the trend of group operation through the Internet as part of their work.[5]

Optimize the enterprise financial management mode. The enterprise group as an important participant of the market economy, with its strong strength and financial management ability, which requires financial management of enterprise group can have a profound understanding of the Internet, not only to clear the Internet application in financial management advantages, also need to prevent and against some of its weaknesses. On the improvement of the enterprise group financial management mode, first of all need to be centralized management in the primary position to optimize the financial management model of group enterprise, try to play Internet information advantage, the effective integration of financial information distribution through effective information calculation to ensure financial management tasks reasonably, avoid dealing with different departments a work situation, resulting in reduced damage to financial management. In addition, the enterprise group can also integrate the advantages of resources through the Internet, the existing resources and other enterprises for technology sharing and docking, so as to realize the electronic management of the financial management of the enterprise group, which can guarantee the enterprise financial management in the Internet to learn advanced knowledge and technology experience to continuously enhance the management environment. The ability and level of their own, also can through the Internet and between the Promotion Development Group subsidiaries and the parent company, to ensure coordination between the quality of financial management and various departments.

In addition, the enterprise group in order to ensure the effective operation of the capital, we need to ensure the correctness and effectiveness of relevant financial and capital data before it needs to work in the same department, so as to avoid the lack of coordination between different departments and poor communication situation. Therefore, this requires groups of enterprises in the management model and work arrangements can be associated with the characteristics of the enterprise, through the Internet management model and management software, memory allocation and coordination.

Establish a perfect financial management information system. Perfect information system is the foundation and key enterprises to carry out the work of financial management. It can guarantee the financial management of the enterprise group through the information system effectively and accurately the enterprise financial management and Internet technology organic docking. In the rapid development of Internet technology nowadays, enterprises can build the Internet platform for businesses and consumers outside factors such as effective communication, through first hand data and data analysis and sorting, realize the grasp and use of the data, which helps to create a perfect management information system [6]. Through the analysis of the first hand data, financial management staff can accord to the data for effective analysis of enterprise financial and capital expenditure, which, as a basis for improving the enterprise's business strategy and financial management. Internet technology as the basis of Economic Development Corporation, said the network platform construction in an important position in the financial management and the development of enterprises, and in the Internet environment, the advanced information system construction and financial management knowledge.

Improve the safety of financial management. For the enterprise financial security on behalf of the enterprise sustainable development, so the enterprise group in the Internet will be applied to the financial management of the enterprise, need to carry on the effective evaluation and learn the advanced experience of Internet information security at home and abroad in various areas, to prevent leakage of unnecessary financial information in financial management. Cause serious negative influence on the group. Secondly, enterprises also need to continue to work in the increase of information security investment, promote enterprise through scientific research or technical institutions and enterprises long-term cooperation to ensure the safety of their financial management information. Finally, the group enterprise can also strengthen the link with the judicial organs, and increase the security of enterprise financial management information.[7]

In short, the Internet technology in the financial management of the enterprise group not only can play a great role in promoting, improve financial management level of enterprises, but also need to 
face up to the Internet in the group enterprise financial management problems, timely rectification, ensure the safety of financial management.

\section{References}

[1]Xiong J Q. Financial Administration Front Question Discussion of Enterprise Group[J]. Journal of Jiangxi Institute of Education, 2005.

[2]Zhou T. Discussion on Strategy Cost and Financial Risk Management in Coal Enterprise[J]. Shanxi Coking Coal Science \& Technology, 2009.

[3]Wang X D. Discussion on Development of Enterprises' Strategic Management Theory[J]. Journal of Hepatology, 2015, 52(3):261-265.

[4]Cresswell M, Naser G. Discussion on "A water resources management strategy for small water districts -- a case study of the South East Kelowna irrigation district"[J]. Canadian Journal of Civil Engineering, 2013, 40(6):499-507.

[5]RayneSierra. Discussion on "A water resources management strategy for small water d. [J]. Canadian Journal of Civil Engineering, 2013, 40(6):499-507(9).

[6]T he A sia P acific COPD R oundtable G roup. Global Initiative for Chronic Obstructive Lung Disease strategy for the diagnosis, management and prevention of chronic obstructive pulmonary disease: An Asia - Pacific perspective[J]. Respirology, 2005, 10(1):9.

[7]Cui Z, Zhang F, Chen X, et al. On-farm evaluation of an in-season nitrogen management strategy based on soil N min, test[J]. Field Crops Research, 2008, 105(1 - 2):48-55. 